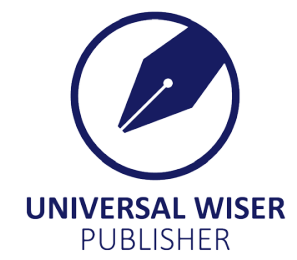

\title{
Language Choice Among Commuter Bus Conductors (Drivers' Mates) and Passengers at Kumasi Kejetia Bus Terminal, Ghana
}

\author{
Isaac Oduro $^{1^{*}}$, Mercy Asantewaa ${ }^{2}$, Olivia Donkor ${ }^{1}$, Francis Kwadwo Kusi ${ }^{1}$, Wilson Oduro ${ }^{3}$, Felicia \\ Asamoah-Poku ${ }^{4}$ \\ ${ }^{1}$ Department of Languages, Saint Monica's College of Education, Ghana \\ ${ }^{2}$ Department of Languages, Toase Senior High School, P.O. Box 14, Nkawie \\ ${ }^{3}$ Department of Languages, E. P. College of Education, P, O . Box AM. 12, Amedzofe, V/R \\ ${ }^{4}$ Department of Languages, Saint Louis College of Education, P. O. Box 3041 \\ Email: isaacoduro1970@yahoo.com
}

\begin{abstract}
This research aims to examine the language used by the commuter bus conductors and passengers moving to and from Kejetia bus terminal in the Kumasi Metropolis, Ghana. This research basically focuses on sociolinguistics approach. The source of the data is purely the utterances of the bus conductors and the passengers on board in the commuter buses. Observation and recording were used as the data collection instruments in the study. Both qualitative and quantitative methods were used to analyze the data gathered. The study found Asante Twi dialect as the most dominant language choice of the majority of the sampled population (passengers and drivers' mates). The use of unmarked code switching in conversational discourse was not uncommon among participants. Finally, the study found English language to be the second most dominant language choice in the participants' verbal discourse. The implication is that apart from Akan language, all the other seven languages stand the risk of experiencing language shift leading to eventual language death should the ethnic groups concerned fail to maintain their languages.
\end{abstract}

Keywords: utterance, sociolinguistics, verbal discourse, dominant language choice, commuter bus

\section{Introduction}

Language and society are two inseparable entities which cannot be divorced because language is used to disseminate social information. Conversely, society also thrives well through language usage. Language choice is a determinant for the development of any society. Every individual needs to make a choice that will help him / her to fulfill all his / her communicative needs in the most appropriate way ${ }^{[1]}$.

Consequently, Seli ${ }^{[2]}$ posits that in any conversation, bilingual speakers choose among the languages available to them. It is very important to make choice that will suit one's conversation especially when there are many linguistic repertoires at one's disposal ${ }^{[3]}$. This will definitely facilitate the necessary understanding between the parties involved in that discourse if the parties can equally display their communicative competence in the selected code. If on the other hand, one party decides to make a choice and participants involved in the conversation do not understand, there will be either no communication at all or a total miscommunication.

In line with Nurfadila, Sariono and Hariyadi ${ }^{[4]}$ and Sobral ${ }^{[5]}$, the individual cannot engage in communication without making a choice of code he / she is competent in, in his / her community. For someone to engage in effective communication there is the need to make a choice, as Fishman ${ }^{[6]}$ put it: 'Who speaks what language to whom and when?' Sithole ${ }^{[7]}$ sees language choice to be very common among bilingual and multilingual individuals. Therefore, on one breath, individuals in multilingual community should consider those involved in the conversation and reasons for the engagement before choosing any language as a conversational tool ${ }^{[8]}$.

Similarly, one cannot just come out with any language choice without considering the parties involved and the purpose for the conversation ${ }^{[9]}$. Though language choice is more functional in both bilingual and multilingual communities yet monolinguals can also exercise language choice for the purpose of developing language. Monolinguals also have to consider participants whom they are conversing with and the reasons they are conversing so that they can make a very good choice within the same language, dialect or registers to send their messages across ${ }^{[8,10]}$. 
Individuals make choice for different purposes. They choose words, registers, and languages that will help them communicate idea ${ }^{[11-12]}$. It should be understood that people do not communicate for communication sake but to share ideas or to send information. This means if the one you are communicating with doesn't understand your choice of language, then the person will not get the import of your message and act accordingly. In line with this, people have been using code switching and code mixing in their daily conversations to put the messages across in order to be properly heard and understood.

Code-switching and code mixing have been classified as the phenomenon in Bilingual and Multilingual societies where language contact is so predominant. This means that code switching and code mixing is a significant feature in multilingual community where its' concurrent usage accounts for each other due to linguistic deficiency when two or more persons engage in conversational discourse ${ }^{[13]}$. Some researchers consider the two as an interface of the other and therefore use them synonymously or interchangeably ${ }^{[14]}$. For instance, $\mathrm{Kami}^{[1]}$, refer to the two as "code hybridization." However, other researchers also draw both functional and structural dichotomy between the two $\operatorname{codes}^{[15-17]}$. Regardless of the different ideologies researchers hold on code switching and code mixing, the two have been indispensably established and accepted by researchers as the existing feature of multilingual and bilingual communities.

This phenomenon of code mixing is a common practice among Commuter Bus Drivers' Mates in Ghana, particularly in Kumasi. It is imperative to note that many people have always been using commuter bus as a means of transport to commute from one suburb to another for the purposes of transacting business. Drivers' mates in this sense could either be males or females who play assistive roles by collecting fares and also alerting drivers when a passenger is alighting. Another traditional role the mates perform is to pack all the luggage passengers on board are travelling with. In the commuter bus, all kinds of interactions go on between the drivers' mates and the passengers. For instance, if a passenger wants to alight, he or she will have to tell the driver's mate for him or her to alert the driver. The drivers' mates also engage passengers in conversation while demanding the lorry fare from them before they alight at their various destinations. Researchers must therefore be concerned about the medium of conversation in these commuter buses. However, studies in this area are largely scanty in Ghana and by extension Africa irrespective of its relevance. In the quest of finding answers, the study poses the following questions: Do people on board resort to the use of Twi alone? Do they employ different code intentionally or unintentionally?

\subsection{The theoretical framework underpinning this work}

This research employed "Markedness Model" put forward by Myers-Scotton ${ }^{[18]}$. This theory is in relation to the choice of one linguistic code (language) often used by a speaker over the use of other code in multilingual environment. In this theory, Myers-Scotton explains that in the multilingual society, the speaker has what she calls rights-and-obligation (RO) to select a particular code over the other in any conversational discourse. Certain variables such as change of participants in conversational engagement, social status of participant such as education, pride in speaking a particular language, and the environment one finds him or herself can most likely influence the selection of one code over the other. One important thing about this model is that, the choice of a particular language is a clear indication of the speaker's involvement within the conversational discourse ${ }^{[8]}$.

Myers-Scotton further explains that the markedness model is a set of two code choices which are 'marked' and 'unmarked'. The model further elaborates that in conversational discourse, participants will either make marked and unmarked choice depending on many situational factors ${ }^{[19]}$. Generally speaking, speakers of any linguistic environment make more unmarked choices either consciously or unconsciously than the marked ones. This phenomenon is also based on the particular situation on hand. Whiles the 'unmarked' choices are linguistic choice of code which do not deviate from the norm of the speech community, the 'marked' ones are quite opposite. The marked choices are those codes which are unacceptable as being part of the norms of the speech community ${ }^{[20]}$.

A speaker will definitely use the unmarked code if the person engaged in the conversational discourse has the same linguistic background as the speaker. In the light of this, sameness of the linguistic background gives each participant the right of obligation to choose the unmarked code ahead of the marked one ${ }^{[21]}$. The markedness model works to the fullest where there is a situation a speaker in the linguistic community has to contend with. Though whatever choice a speaker makes in a particular situation, Myers-Scotton affirms that there are "potential costs and rewards of all alternative

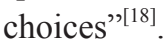

The above assertion made by Myers-Scotton simply suggests that the speaker or participants in any conversational situation are completely free to choose any code in conversational engagement because it is his / her Right of Obligation to do so. And then the main principle governing the markedness model is negotiation ${ }^{[22]}$. This simply means that the speaker's choice of using any code in conversational situation is a means of negotiating the RO that should activate and dominate 
in a certain conversational engagement. The maxims which come with the principle of markedness are three. These are unmarked-choice maxim, marked-choice maxim and the exploratory choice maxim ${ }^{[18,23-24,30]}$.

The unmarked code switching has two main types. Thus, the sequential unmarked code switching and the marked code switching. In the sequential unmarked code switching, the conversation is motivated by situational factors such as changes in participants and different locations or domains in which the conversation takes place ${ }^{[25]}$. Conversely, that of marked code switching is also motivated by the engagement of participants in the conversation resorting to continuous pattern of using two or more languages ${ }^{[26-27]}$. This often results in intra-sentential code switching which is the characteristic of the unmarked code switching. The motivating factor in using this model stems from the fact that language choice could either be directly or indirectly influenced by this markedness model. Aside the above reason, linguists such as Essegbey ${ }^{[28]}$ and $\mathrm{Ansah}^{[29]}$ also used the model to explore language choice in their various research works which have yielded remarkable results.

\section{Materials and methods}

\subsection{Socio-cultural characteristics of the study area}

The Kumasi Metropolitan, popularly abbreviated as KMA, was established in way back 1860 by the then Asantehene Prempeh 1. Currently, the Kumasi Metropolitan Assembly is among the 260 Municipal, Metro and District Assemblies in Ghana. In the Ashanti region, the Kumasi Metropolitan Assembly is one of the twenty-seven (27) districts. Interestingly, Kumasi is the administrative capital of the Ashanti region and it is the second largest capital city of Ghana.

It is estimated that, the Kumasi Metropolitan Assembly covers the land stretch of about 299 kilometers square. In all, there are nine (9) sub-metros in the KMA. These sub-metros are: Asokwa, Bantama, Kwadaso, Manhyia, Nhyiaeso, Oforikrom, Suame, Subin and Tafo. It shares boarders with some notable municipals and districts such as Ejisu / Juabeng Municipal, Awima Nwabiagya North district, Kwabre East districts, Bosomtwi etc. (www.ghanadistricts.com)

The total population of the Kumasi Metropolis stood at 2,035,064 as at 2012 (2012 Population and Housing Census). Even though, the population of the Kumasi Metropolis is predominantly Akans, constituting $74.9 \%$ of the total population, yet there are some $25.1 \%$ other ethnic groups living in Kumasi. In terms of the percentage distribution of these ethnic groups, this is how each group stands: Ga-Dangme, $0.9 \%$, Ewe, 3.5\%, Guan, 2.5\%, Gurma, 1.0\%, Mole-Dagbon, 11.0\%, Grusi, 2.5\%, Mande, $2.1 \%$, others (representing other languages other than what has been stated of which English is included) $1.7 \%$, respectively.

The percentage figures shown above conclusively suggest that the most functional language spoken is no doubt Akan (Asante Twi) which more or less is the language choice. However, one thing that must not be lost sight of is the fact that the languages of other ethnic groups which constitute the $25.1 \%$ percent cannot be a push over at all in terms of their functionalities in this multilingual community such as Kumasi.

\subsection{Research design}

The research design for the study was a cross-sectional approach premised on interpretivist methodology. This study was an ethnocentric. Primary data was the main source of data for the study. Passengers of Commuter bus and bus conductors (drivers' mates) were the target population for the study. Researcher selected 220 participants for the study based on the principle of saturation. The tools mainly employed in data collection were qualitative. The specific instruments used to gather the data were observation and voice recording. The researchers engaged in covert observation while on board with passengers and bus conductors (drivers' mates). The researchers intentionally boarded the commuter buses from the bus terminals to their destinations to observe and record conversations between passengers and drivers' mates. It took the researcher thirty days to gather the needed data.

The recording was done in two folds. Mobile phone was used to record the passengers' conversations. Other utterances made were also written in a note pad. The data population comprised two categories of persons, namely, passengers and bus conductors (drivers' mates) of which about $90 \%$ consisting of $65 \%$ illiterate and $25 \%$ semi-literates. The other $10 \%$ were the few educated elites on board. In all, two hundred and twenty (220) participants were sampled for the study. The passengers numbered two hundred out of which a hundred and twenty (120) were females and the remaining eighty (80) were also males. The remaining twenty (20) were bus conductors (fifteen (15) males and five (5) females). In all, five hundred and seventy-six (576) utterances were made by two hundred and twenty (220) participants. The recorded voices were played over and over again and were accurately transcribed into readable materials. All the co-authors consciously read through the transcribed materials to authenticate its acceptability. Corrections were also made in the hand written data before the data was ready for use. In all, the author used all the five hundred and seventy-six (576) utterances 
(words) to carry out the analysis.

\subsection{Data analysis}

This section deals in details with the analysis of the data collected. The researcher coded and thematically analyzed the data according to the objectives of the study. The qualitative data were presented in quotations while percentages were used to descriptively analyze the quantitative data.

\section{Results and analysis}

A total of five hundred and seventy-six (576) words were uttered by the sample population (passenger and drivers' mates) on board. The total population was two-hundred and twenty (220) consisting of two-hundred (200) passengers and twenty (20) drivers' mates (bus conductors) on board. Table 1 shows the total number of words uttered by both the drivers' mates and the passengers.

Table 1. Showing data classification of utterances of the participants

\begin{tabular}{cccc}
\hline Participants & No. of words & Percentage & Average words uttered per day \\
\hline Passengers & 272 & 47.2 & 9.1 \\
Mates & 304 & 52.8 & 10.1 \\
Total & 576 & 100 & 19.2 \\
\hline
\end{tabular}

Source: Field Survey, 2020

As seen from the Table 1, out of the 576 utterances by the participants within the period, 304 words were uttered by the drivers' mates representing 52.8\%. The average words uttered per mate per day stood at 10.1 words. On the part of the passengers on board, a total of two hundred and seventy-two (272) words were uttered representing 47.2\%. The average words uttered per day also stood at 9.1 words.

\subsection{Bus conductors' (drivers' mates) language choice}

Table 2 below shows the distribution of the language choice and percentage marks exhibited by the drivers' mates (bus conductors) during the period. A total of one hundred and ninety-eight (198) Twi words were uttered representing 65.1\% while one hundred and six (106) English words were uttered representing 34.9\%.

Table 2. Showing bus conductors' (drivers mates') language choice

\begin{tabular}{ccc}
\hline Language Choice & No. of words uttered & Percentage \\
\hline Twi & 198 & 65.1 \\
English & 106 & 34.9 \\
Total & 304 & 100 \\
\hline
\end{tabular}

Source: Field Survey, 2020

\subsection{Passengers' language choice}

The Table 3 below presents the distribution of the language choice used by the passengers. Two hundred and seventytwo (272) words were uttered by the passengers. Out of the 272 words uttered, 197 (One hundred and ninety-seven) words were uttered in Twi whereas the other seventy-five (75) words were also uttered in English Language.

Table 3. Showing distribution of passengers' language choice

\begin{tabular}{ccc}
\hline Language Choice & No. of words uttered & Percentage \\
\hline Twi & 197 & 72.6 \\
English & 75 & 27.4 \\
Total & 272 & 100 \\
\hline
\end{tabular}

Source: Field Survey, 2020

\subsection{How the language choice was uttered}

In this section, the data is characterized with both code mixing and code switching. In all, three language patterns have been identified in the data presented. Pattern A as presented in data 3.3.1 and 3.3.2 consist of tag code mixing where the Twi lexical items dominate that of English lexical items in each of the structures. Another language pattern is also 
presented in data 3.3.3. In this data, the English lexical items are also more than the Twi lexical items in the utterance in pattern B. Pattern C gives a representation of only English language lexical items in the utterance as presented in data 3.3.4 below. Per the patterns identified, there are some sort of similarities and differences in them. In terms of differences, a set of phrases or phrase (tags or tag) in one language is / are inserted into an utterance as seen in data 3.3.1 \& 3.3.2. and 3.3.3. Data 3.3.4 presents seemingly similar language lexical items in the structures which is entirely different from data 3.3.1 \& 3.3.2.

The data collected simply showed that some of the bus conductors (drivers' mates) used code mixing in their utterances because the use of words was characterized with changing varieties across phrases boundaries. One outstanding phenomenon in all the code mixing used by the participants was a particular choice of language that dominated their interactions. The examples below drawn from the data showed that the Asante Twi was the dominant language which was mixed with the English language. See Data 1 for more details.

\subsubsection{Data 1}

1. YE-re-n-nyina traffic no ase.

We-FUT-NEG-stop traffic DEF down.

We will not stop at the traffic. (FT)

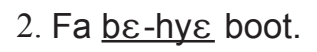

Take will-put boot.

Bring and put it in the boot. (FT)

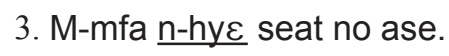

NEG-take NEG-put seat DEF under.

Do not put it under the seat. (FT)

4. Me-de fifty pesewas a-ka ho.

1SG have fifty pesewas PRF-added it.

I have added fifty pesewas to it. (FT)

5. Door no $\underline{b \varepsilon f \varepsilon}$ wo nsa.

Door DEF FUT-damage your hand.

The door will damage your hand. (FT)

6. Maame, fa duster no ma me.

Mother, take duster DEF give $1 S G$.

Mother, please get me the duster. (FT)

7. Maame, wo nnooma no $\varepsilon-y \varepsilon$ a ma me three cedis.

Mother, 2SG luggage DEF 3SG-good CONJ give 3SG three cedis.

Mother, please give me three cedis for your luggage. (FT)

8. N-ntena ho na heat wo $\underline{\text { ho }}$.

Neg-sit there FOC heat is there

Don't sit there, for the place is heated. (FT)

9. Yes, nnooma no sika

Yes, things DEF money

Yes, please bring your luggage fare. (FT)

10. Maame, fa forty pesewas be-gye one cedi.

Mother, bring forty pesewas will-collect one cedi.

Mother, please bring forty pesewas for one cedi. (FT) 
In Data 1, the drivers' mates employed intra-sentential code mixing though the dominant code was Asante Two. A critical look suggests that, some of the utterance varieties change across phrases boundaries, as seen above, thus (1-10). Readers can see the mixture of both Twi words in all of the sentences above.

Data 2 below also shows that the passengers on their part resorted to the use of intra-sentential code mixing in some of the utterances made. The data suggest that the participants used purely Twi with some mixed varieties of English vocabularies across phrases boundaries of the Twi words in a single sentence as seen in example (11-20) in Data 2 below.

\subsubsection{Data 2}

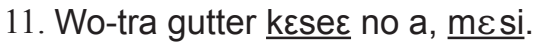

2PL-pass gutter big DEF that 1SG-alight.

I will alight after you go pass the big gutter. (FT)

12. Kaa no a-nya fault anaa?

Car Det PRF-get fault or?

Has the car developed any fault? (FT)

13. Me nnooma no hye seat no ase?

1SG luggage DEF locate seat DEF under?

Are my luggage under the seat? (FT)

14. Aden? Wo-n-ni coins?

Why? 2SG-NEG-have coins?

Why? Don't you have some coins? (FT)

15. 'Mate, $\underline{\text { mesre }}$ wo so baby no mu ma me'.

'Mate, 1SG-beg 2PL hold baby DEF in for 1SG.

'Mate, please hold the baby for me'. (FT)

16. Me-foro-o kaa no baabi a water tank no si no.

1SG-board-PST car DEF place REL water tank DEF locate DET...

I boarded the car where the water tank is located. (FT)

17. 'Mate', to door no mu'.

'Mate, close door DEF in.

'Mate, please close the door. (FT)

18. Driver no se me-nsi fam.

Driver DEF says 1SG-alight down

The driver says I should alight.

19. Fa basket no si boto no so.

Take basket DEF place sack DEF on

Put the basket on the sack. (FT)

20. $\underline{\text { HwE }}$ na door no ammo me.

Ensure that door DEF it-NEG-hit 1SG.

Ensure that the door doesn't hit me. (FT)

From the examples above, it is seen that the dominant language choice was Akan mixed with some underlined English words in any of the sentences.

Data 3 below also shows another intra-sentential code mixing in different lexical arrangement in a sentence where English language words were mixed with Twi varieties across phrase boundaries. The examples from data 3: reveal that the participants mixed Twi words in the English sentence as seen in examples (21-26) below. 


\title{
3.3.3 Data 3
}

21. Boy hyع front.

Boy, be front

Boy, be at the front. (FT)

22. Master, ye wild.

Master, be wild.

Master, be wild. (FT)

23. Front gye coins

Front collect coins.

Passenger at the front, please, have your coins. (FT)

24. M- $\varepsilon$-si children's park.

1SG-will-alight children's park

I will alight at children's park. (FT)

\author{
25. Mo lorry fare. \\ 2PL lorry fare \\ Please, bring your lorry fare. (FT)
}

\section{Me-tua two cedis. \\ 1SG-will-pay two cedis \\ I will pay two cedis. (FT)}

One interesting phenomenon that has been observed from the data is that, sometimes the sentences begin with Twi lexical items or vocabularies as can be seen but the English vocabularies or lexical items dominate the sentence.

\subsubsection{The use of english language alone as a choice (code switching)}

Data 4 suggested that, there are instances where English Language alone was used as a choice by the participants in the interactional discourse. The phenomenon which prevailed in the interaction showed that varieties of codes changed across sentences boundaries. It was observed that, the participants started and ended a conversation with a variety of languages and across sentence boundaries; a new variety of language was also used. Examples in Data 4 showcase this phenomenon.

\subsubsection{Data 4}

\section{Back seat ten cedis \\ 28. Yes front \\ 29. One cedi \\ 30. Yes back seat \\ 31. Five cedis front}

The examples in the data confirm how participants switched from Asante Twi to English language as the interaction proceeded.

\subsection{Discussion}

The foregone survey appears to have revealed the following about the topic under consideration. Thus, at the end of the analysis, the following findings have been authenticated. It has been revealed that Asante Twi is the language choice by the majority of the participants selected in their interactional engagements. This confirms that the Asante Twi is the most dominant language choice used amongst the passengers in commuter buses in Kumasi metropolis. This comes as no surprise as the Akans out-number the other ethnic groups in the demographic area of the study. This study also confirms Ghana Statistical Service (2012) report that the Akan language is spoken by majority of Ghanaians in Ghana. It also affirms Ansah's claim that the Akan language is widely spoken by the majority of Ghanaians ${ }^{[22]}$.

The data analysis revealed that both the passengers and the bus conductors (the drivers' mates) made some utterances in Asante Twi in their conversational discourse more than any other languages. The educational background of the bus 
conductors (drivers' mates) and the passengers on board might have accounted for the use of the unmarked code as majority of them were school drop outs. Not only did some of them drop out of school, but also majority of them could hardly read or write their own language let alone the official language (English language). In reference to the data break down, $65 \%$ were illiterates, $25 \%$ were semi-literates, whereas $10 \%$ represented the educated elites. This made them resort to the use of unmarked code considering variables like location, purpose of conversation and the linguistic repertoire of the participants on board as confirmed by [18].

Careful observation of the data analyzed also indicated clearly that the language choice (Asante Twi) that mostly dominated the interactional engagements of the participants was affected by the domain of the interaction. Here, demography played a major role. Kumasi metropolis is the capital city of the Ashantis and for that matter they speak the mother tongue more fluently than any other language. This assertion confirms [4] and [5] claim that, the individual makes a choice of code she or he communicates in his or her community.

Beside code mixing, another phenomenon called code switching was characterized in the participants' engagements. As identified, these varieties of languages were used in sentences boundaries. This revelation is in line with what Afifah ${ }^{[12]}$ and $\operatorname{Sahan}^{[11]}$ have already posited that people choose words, register, and language that will help them communicate ideas. It also confirms the earlier assertions made by [13] that the concurrent use of code switching and code mixing in multilingual community accounts for each other due to either linguistic deficiency of the speaker in a conversation or superior differential command competence of a particular code a participant chooses in a conversation.

Another finding the study cannot be silent on is that both code mixing and code switching were governed by certain factors such as environment, participants and the linguistics repertoire of the participants in the communication process. Here, the environment simply suggests a particular location where the interaction goes on. In this regard, the cosmopolitan nature of Kumasi metropolis no doubt could trigger the participants to either switch or mix code when they are engaged in interactional discourse. Participants also either switch or mix code due to certain number of factors such as showing of social class, vocabulary alternation and differential command competence. This finding is in agreement with the proposition that participants in oral engagement discourse may more likely resort to continuous pattern of using two or more languages in a multilingual community where language contact is eminent ${ }^{[26-27]}$.

It has also been established that even though participants mixed and switched codes at certain stages in their communication discourse, yet there was no misunderstanding exhibited by many participants. The manifestation of the English language L2 mixed with the Akan L1 is a clear indication of the language situation in Kumasi as most of the indigenes speak little English more than any other language. In this regard, participants feel more relaxed when they mixed Twi and English in a discourse.

\subsection{Conclusion and policy implication}

In conclusion, per the data collected and analyzed, it has been established that even though Kumasi Metropolis is a multilingual community with about nine different functional languages, comprising Akan, Ga-Dangme, Ewe, Guan, Gurma, Mole Dagbon, Grusi, Mande and others, yet the only dominant language choice among the passengers and the bus conductors (drivers' mates) on board as per this research is the Asante Twi, a major dialect of the Akan language. In the domain of this research, the English language aside Asante Twi, surprisingly was the language choice among the participants more especially the bus conductors (drivers' mates) and a few educated elites on board. This revelation is exponentially potential to bring about language shift in the seven non-Akan languages which can lead to its' eminent death eventually. However, the seven ethnic groups as a matter of urgency must resort to intensive language maintenance to protect their languages from being endangered, shifted and possibly its' eventual death. The findings also have some educational policy implications. Since modernity is gradually shifting the language choice of the people, the educational system of the country should be tailored to prevent the extinction of the native language (Asante Twi). Again, relevant training programmes could be organised by the Transport Unions for these bus conductors. This will help in the daily transactions between the bus conductors and the passengers. Adult education is also relevant in ameliorating high levels of illiteracy among bus conductors and passengers.

\section{References}

[1] Kami, P., Simpen, I. W., Yadnya, I. B. P., Laksana, I. K. D. Language choice of ende-nage speakers. The International Journal of Language and Cultural. 2020; 2(1): 58-74.

[2] Seli, S. Language choice and attitude in sumatran-javanese intermarriage families in relation to language maintenance in lubuklinggau. Journal of English Education, Literature and Linguistics. 2020; 3(1): 116-130. 
[3] Akbar, M. A. Family language policies of families with deaf children in Singapore. 2020.

[4] Nurfadila, Y., Sariono, A., Hariyadi, E. Pemilihan bahasa pada masyarakat etnik jawa di dusun gumuk banji, desa kencong, kecamatan kencong, kabupaten jember. Semiotika: Jurnal Ilmu Sastra dan Linguistik. 2020; 20(1): 33-44.

[5] Sobral, S. R. The first programming language and freshman year in computer science: Characterization and tips for better decision making. 2020.

[6] Fishman JA. Who speaks what language to whom and when? La linguistique. 1965; 1: 67-88.

[7] Sithole, E. Challenges Encountered on the Rekete ChiNdau-Leave a Legacy Facebook Page. Language Matters. 2020; 51(1): 3-21.

[8] St. Cyr Brisini, K., Solomon, D. H. Building Expertise: Effects of Experience Claims on Responses to Advice. Journal of Language and Social Psychology. 2020.

[9] Zuraida, L., Budiarsa, M., Darmalaksana, I. K., Simpen, I. W. Bilingual acquisition on children's language choice. The International Journal of Social Sciences World. 2020; 2(1): 27-40.

[10] Ko, B. A. Expressing modalization in EFL college learners' writing: From modality system of systemic functional grammar. Sociolinguistics. 2020; 28(1): 1-28.

[11] Sahan, K. Variations of English-medium instruction: comparing policy and practice in Turkish higher education. Doctoral dissertation, University of Oxford; 2020.

[12] Afifah, N. An analysis of politeness principles used by main characters in "The Giver" novel by Lois Lowry. Doctoral dissertation, IAIN Kediri; 2019.

[13] Nasution, V. A., Ayuningtyas, N. The language choice of chinese community in medan: A sociolinguistics study. Joall. Journal of Applied Linguistics \& Literature. 2020; 5(1): 11-25.

[14] Pawiro, M. A., Andriany, L. Language choice by bilingual speech community of acehnese in family domain in medan: A case study. International Journal of Applied Linguistics and English Literature. 2019; 8(6): 9-15.

[15] Setiawan, B. Emotional switching in children's speech: A case study of emotion change causing a code-switching in education domain. In 4th International Conference on Arts Language and Culture (ICALC 2019). Atlantis Publishing; 2020. p.574-579.

[16] Sanden, G. R. Language policy and corporate law: A case study from Norway. Nordic Journal of Linguistics. 2020; 43(1): 59-91.

[17] Siwina, P., Prasithrathsint, A. Multilingual landscapes on thailand's borders. Journal of Mekong Societies. 2020; 16(1): 112-131.

[18] Myers-Scotton, C. Social motivations for code switching: Evidence from Africa. Oxford: Oxford University Publishing; 1993.

[19] Taylor-Leech, K. Timorese talking back: The semiotic construction of chronotopes in the Timor Sea protests. Linguistic Landscape. 2020; 6(1): 29-51.

[20] Tianxiao, W. Family Language Policy and Sibling Variation among Bilingual Chinese Singaporeans. 2019.

[21] Kushartanti, B. The Linguistic Choice by Indonesian-Speaking Adolescents: A Case Study in Tangerang. Linguistik Indonesia. 2020; 38(1): 23-34.

[22] Abdelhay, A., Makoni, S. B., Severo, C. G. Chapter one language planning and policy: the discursive landscaping of modernity1. Language planning and policy: Ideologies, ethnicities, and semiotic spaces of power. $2020 ; 1$.

[23] Fitriati, A., Wardani, M. M. S. Language attitudes and language choice among students in yogyakarta: A case study at Universitas Sanata Dharma. International Journal of Humanity Studies. 2020; 3(2): 239-250.

[24] Trinanda, B. E., L., A. Language choice among females in EQWIP HUBs Community. Language Horizon. 2020; $7(1)$.

[25] Powell, R. Conceptualising and Contextualising Malaysian Bilingual Law. In language choice in postcolonial law. Singapore: Springer; 2020. p.1-23.

[26] Powell, R. Political and Economic Influences on Multilingualism and Multijuralism. In Language Choice in Postcolonial Law. Singapore: Springer; 2020. p.25-60.

[27] Powell, R. Language choice in postcolonial law. Language Policy. 2020.

[28] Essegbey, J. On Assessing the Ethno linguistic Vitality of Ga in Accra. In: Fiona Mc Laughlin. (ed.) The Languages of Urban Africa. London: Continuum; 2009. p.115-151.

[29] Ansah, N. "Re-examining the fluctuations in Language in-education policies in post-independence Ghana". Multilingual education. 2014; 12: 1-15.

[30] Abzach, L. Effects of advertisement's language choice, generation and consumer's level of acculturation in ethnic marketing to Turks in the Netherlands. 2019. 